\title{
$\mathbb{N}<\mathrm{IT}$
}

Karlsruhe Institute of Technology

\section{Demand response through decentralized optimization in residential areas with wind and photovoltaics}

By Thomas Dengiz, Patrick Jochem, Wolf Fichtner

No. 42 | April 2020

WORKING PAPER SERIES IN PRODUCTION AND ENERGY

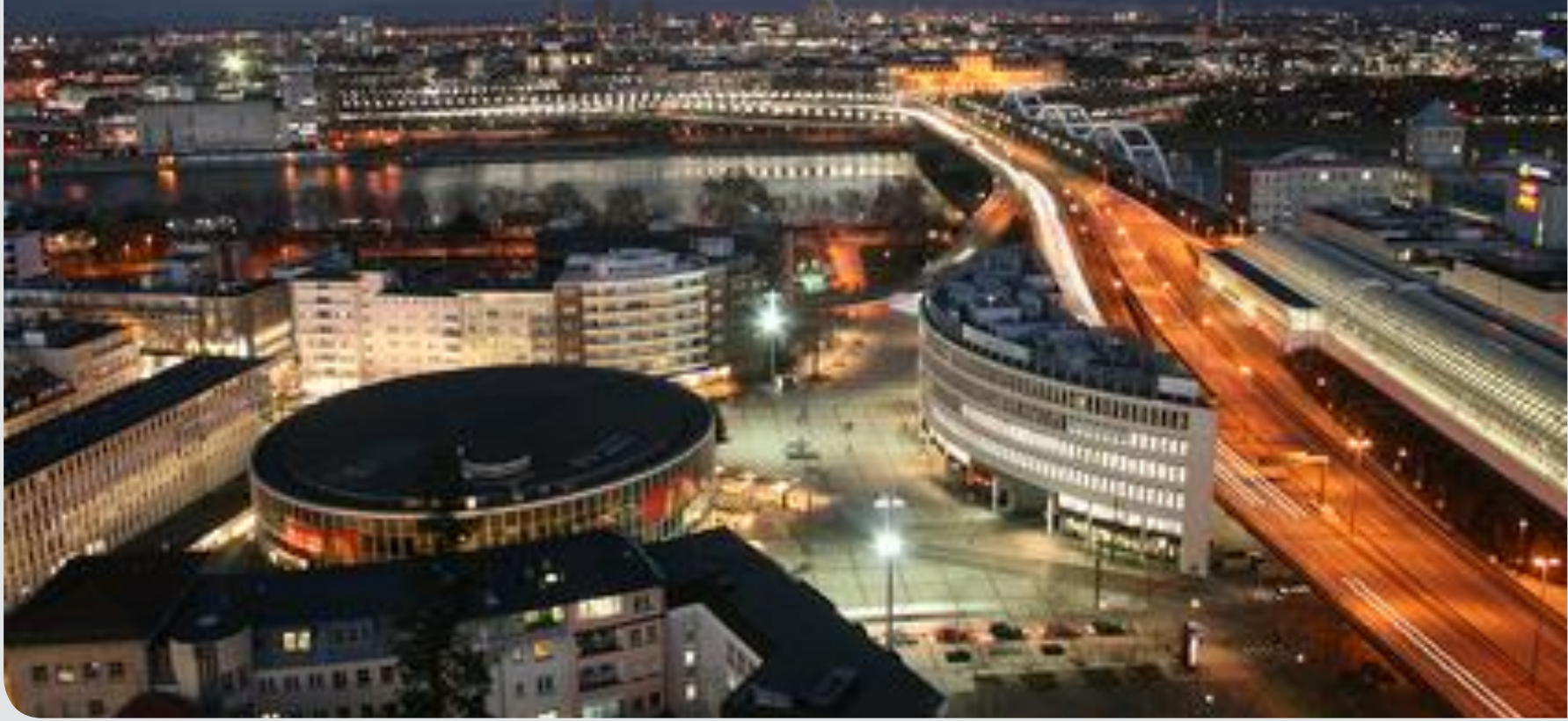




\title{
Demand response through decentralized optimization in residential areas with wind and photovoltaics
}

\section{Thomas Dengiz, Patrick Jochem, Wolf Fichtner}

Chair of Business Administration, Production and Operations Management, Institute for Industrial Production (IIP), Karlsruhe Institute for Technology (KIT), Hertzstr. 16, 76187 Karlsruhe, Germany

*Corresponding author: Thomas Dengiz (thomas.dengiz@kit.edu)

\begin{abstract}
A paradigm shift has to be realized in future energy systems with high shares of renewable energy sources. The electrical demand has to react to the fluctuating electricity generation of renewable energy sources. To this end, flexible electrical loads like electric heating devices coupled with thermal storage or electric vehicles are necessary in combination with optimization approaches. In this paper, we develop a novel privacy-preserving approach for decentralized optimization to exploit load flexibility. This approach, which is based on a set of schedules, is referred to as SEPACO-IDA. The results show that our developed algorithm outperforms the other approaches for scheduling based decentralized optimization found in the literature. Furthermore, this paper clearly illustrates the suboptimal results for uncoordinated decentralized optimization and thus the strong need for coordination approaches. Another contribution of this paper is the development and evaluation of two methods for distributing a central wind power profile to the local optimization problem of distributed agents (Equal Distribution and Score-Rank-Proportional Distribution). These wind profile assignment methods are combined with different decentralized optimization approaches. The results reveal the dependency of the best wind profile assignment method on the used decentralized optimization approach.
\end{abstract}




\title{
Demand response through decentralized optimization in residential areas with wind and photovoltaics
}

\author{
Thomas Dengiz*, Patrick Jochem, Wolf Fichtner \\ Karlsruhe Institute of Technology (KIT), Hertzstraße 16, 76187 Karlsruhe, Germany
}

\begin{abstract}
A paradigm shift has to be realized in future energy systems with high shares of renewable energy sources. The electrical demand has to react to the fluctuating electricity generation of renewable energy sources. To this end, flexible electrical loads like electric heating devices coupled with thermal storage or electric vehicles are necessary in combination with optimization approaches. In this paper, we develop a novel privacy-preserving approach for decentralized optimization to exploit load flexibility. This approach, which is based on a set of schedules, is referred to as SEPACO-IDA. The results show that our developed algorithm outperforms the other approaches for scheduling based decentralized optimization found in the literature. Furthermore, this paper clearly illustrates the suboptimal results for uncoordinated decentralized optimization and thus the strong need for coordination approaches. Another contribution of this paper is the development and evaluation of two methods for distributing a central wind power profile to the local optimization problem of distributed agents (Equal Distribution and Score-Rank-Proportional Distribution). These wind profile assignment methods are combined with different decentralized optimization approaches. The results reveal the dependency of the best wind profile assignment method on the used decentralized optimization approach.
\end{abstract}

Keywords: Demand response, Decentralized optimization, Smart grid, Wind and PV integration, Electric heating, Electric vehicles

\section{Introduction}

As the share of volatile renewable energy sources (RES) like photovoltaics (PV) and wind energy has been increasing in Europe, there is a strong need for demand response to balance demand and supply [1]. Especially electric vehicles (EV) and electric heating devices coupled with thermal storage can react to the intermittent electricity production from RES in residential areas by providing the needed flexibility $[2,3]$. Coupling the electricity sector with the heat and transport sector is a vital step towards using high shares of RES [4]. The demand for heat is the main energy demand in residential areas in most countries. Electic heating devices can use existing infrastructures like hot water tanks or the inertia of building mass to store energy. Thus, their operation can be shifted to times with high generation by RES without affecting the residents' comfort level.

Advanced measurement devices like smart meters and intelligent monitoring and control strategies transform the conventional electricity grid into a smart grid [5]. A smart grid can reduce the curtailment of RES and thus increase the self-consumption rate of locally generated RES. In the year 2018, around

\section{${ }^{*}$ Corresponding author.}

E-mail addresses: thomas.dengiz@kit.edu (T. Dengiz), jochem@kit.edu (P. Jochem), fichtner@kit.edu (W. Fichtner) 
5.4 GWh of electricity production from RES were curtailed in Germany [6]. Wind energy caused about $97 \%$ of the curtailed energy, while the share of PV was approximately $2 \%$. Furthermore, intelligent control approaches can lower the peak load in local grids and thus reduce the stress on the transformers.

Centralized scheduling-based optimization $(\mathrm{CO})$ is often applied in the literature to exploit the electric load flexibilities in residential areas [7]. In CO, a central unit generates schedules for all buildings in a residential area based on demand and generation forecasts and directly controls the flexible devices. While CO leads to the overall best results, it has many significant disadvantages that make its application difficult in real-world scenarios. $\mathrm{CO}$ approaches infringe on the privacy of the inhabitants $[8,9]$ and have a high computational complexity due to the NP-hardness of scheduling problems [10]. Moreover, CO approaches are not robust against single-point failures and cyber-attacks $[9,11]$. Decentralized optimization (DO) approaches, on the contrary, do not depend on a central control unit. Each building only optimizes its own goal based on local information. DO approaches have a higher level of robustness and lead to increased data-privacy while having reduced computational complexity $[8,11]$. However, uncoordinated DO of the single buildings without any interaction with the other buildings in a residential area leads to results that are far away from the optimum for the entire system [9].

This paper has two main contributions. The first one is the development of a novel coordinating DO approach for scheduling-based optimization. We compare our approach to existing ones from the literature, to $\mathrm{CO}$, and to a conventional control approach that is used nowadays. Moreover, we introduce and investigate methods for assigning central wind power profiles to the local optimization problems of different buildings in a residential area. For a large-scale analysis of the developed methods in a variety of scenarios, we use a multi-objective optimization problem that exploits the flexibility of electric heating devices and EVs. This paper is structured as follows: In Section 2, we sum up the related work, and in Section 3, we describe the residential area for our case study and the optimization problem. Section 4 introduces the novel DO approach and wind assignment methods. We show the results of our case study in Section 5 and summarize the paper in Section 6.

\section{Related Work}

We use scheduling-based approaches for exploiting the flexibility of electric heating devices and EVs in this study. These approaches determine an optimal schedule for the operation of the flexible device as the output of an optimization problem. We found several DO approaches for demand response in the literature. Commonly used techniques are decomposition methods [12-15]. A single optimization problem is broken down into multiple smaller optimization problems when using decomposition approaches. This process has to be carried out by a central control unit that defines the optimization problems for the decentralized agents.

Braun et al. [12] and Worthmann et al. [16] use hierarchical model predictive control to coordinate the DO of different agents, and Menon et al. [17] use distributed model predictive control for demand response. The authors of $[8,9,18,19]$ use approaches where no central control unit is present. For the approach introduced by Chang et al. [19], the buildings need to exchange consumption and generation data, which interferes with the privacy of the residents $[12,16]$. Ramchurn et al. [18] use a timedependent price signal and a coordinative optimization mechanism to reduce the costs and the peak load of multiple buildings in a decentralized way. The DO algorithms in $[8,9,20,21]$ are based on creating and coordinating a set of schedules for the local optimization problems of different buildings. 
While a central control unit is necessary in $[20,21]$, the DO approaches by Kolen et al. [8] and Dengiz et al. [9] are based on a set of schedules and do not need a central controller. Kolen et al. introduce a two-stage approach to exploit the flexibility of electric heating devices. In the first step, every agent creates a pool of (near-) optimal schedules by solving their local optimization problems. The buildings afterward coordinate the selection of the individual schedules to optimize a common goal in the local grid. Dengiz et al. extend the coordinating algorithm by Kolen et al. and define a procedure to generate a diverse set of schedules for the problem of maximizing the self-consumption rate of locally generated RES. As we saw potential for improvement, we introduce a novel DO approach in this paper that is based on the coordination mechanism by Kolen et al. and the approach by Dengiz et al. for generating diverse solution sets.

Several studies also apply decomposition methods $[11,22,23]$ to use wind energy for demand response in a decentralized way. In $[24,25]$, the authors use load aggregation methods to aggregate the electrical load and the demand response capabilities of multiple residential buildings to participate in the electricity market. Xu et al. [25] use a stochastic day-ahead economic dispatch model to improve the utilization of wind energy. Shao et al. [24] develop a real-time demand response exchange market that is capable of balancing short-term fluctuations of wind power. In addition to the novel approach for coordinating DO, we introduce methods that distribute the whole wind power profile of a residential area to the local optimization problems of different buildings. To the best of our knowledge, this is the only study that investigates methods for assigning wind power profiles to decentralized agents that apply coordinating DO approaches based on a set of schedules.

\section{Optimization problem for the residential area of our case study}

In this section, we describe the optimization problem for the residential area of our case study. The different building types with their corresponding heating systems are shortly described in Section 3.1, and the multi-objective optimization problem for exploiting the load flexibility potentials is explained in Section 3.2.

\subsection{Different building types and heating systems}

The residential area in our case studies consists of three different building types that all represent single-family buildings. Building type 1 and building type 2 have a high insulation level and use an underfloor heating system (for space heating) and a hot water tank (for domestic hot water) as thermal storage. Building type 1 uses a non-modulating ground-source heat pump and building type 2 uses a modulating air-source heat pump. Buildings belonging to the third category have a mediocre insulation standard and use a combined storage system for space heating and domestic hot water. Their primary heat source is a gas boiler. In addition to that, a modulating electric heating element is used in the combined hot water tank.

Figure 1 displays a schematic view of the residential area's local grid. Some buildings are equipped with a PV system and some have EVs that are charged at home. Furthermore, a wind turbine is connected to the local grid. All buildings use an energy management system (EMS) for controlling the flexible heating systems and the charging of the EVs. A transformer connects the local grid to other grid levels. Table A.1 (Appendix) lists the parameters of the heating systems and the EVs in the residential area. In Section 5.1, we describe how we generate the scenarios for our case study. We use the software tool synPRO that generates realistic synthetic data for the load profiles (demand for electricity, space heating, and DHW) and PV generation [26]. 


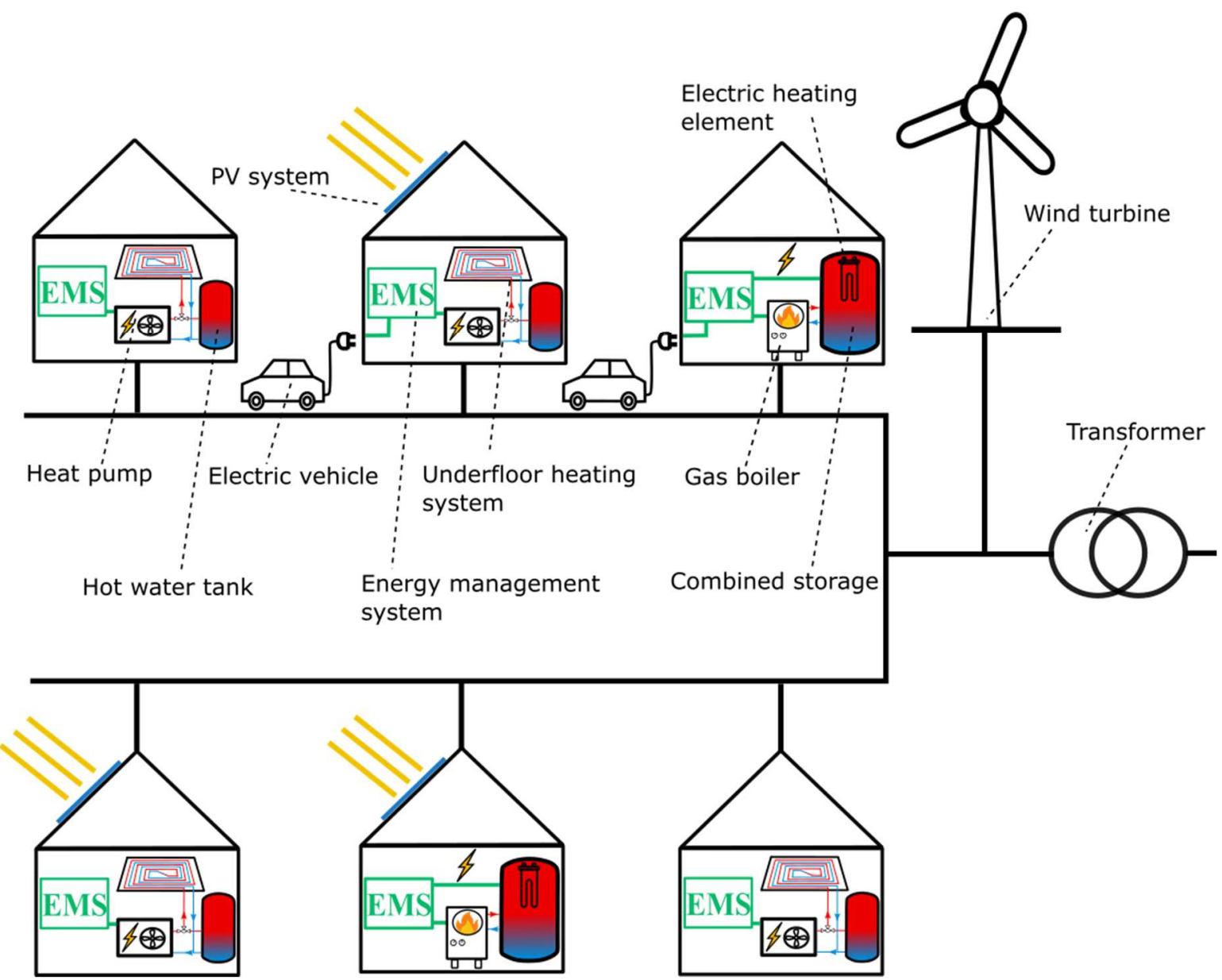

Figure 1: Local grid of the residential area

\subsection{Multi-objective optimization problem}

The buildings in the residential area solve an optimization problem with two objectives. The first goal is to minimize the surplus energy $S E$ and thus to maximize the self-consumption rate of locally generated RES. Further, the buildings intend to minimize their peak loads $P^{P e a k}$. To determine an optimal schedule for the electric heating devices and the EVs, each building solves a multi-objective optimization problem. Eq. (1) shows the objective function for the individual buildings. We combine the two objectives by using a weighted sum approach. Thus, the objective space is transformed into a one-dimensional space and we can apply conventional algorithms for solving single-objective optimization problems [27]. We multiply the two objectives by the two weights $w_{1}$ and $w_{2}$ that sum up to one. To avoid biases caused by different scales of the objectives, we divide each of the objective variables ( $S E$ and $P^{\text {Peak }}$ ) by their corresponding normalized values $\left(S E_{N o r m}\right.$ and $\left.P_{N o r m}^{\text {Peak }}\right)$. These values represent the optimal solution for each of the two objectives if the weight of the other objective is set to zero. They are obtained by solving two auxiliary single-objective optimization problems separately prior to the basic optimization problem with the two objectives.

$$
\min w_{1} \cdot \frac{S E}{S E_{\text {Norm }}}+w_{2} \cdot \frac{P^{\text {Peak }}}{P_{\text {Norm }}^{\text {Peak }}}
$$


The optimization problems have the following constraints:

- Temperature limits of the buffer storage

- Volume limits of the hot water tank

- Heat pump cannot heat up both storages of a building simultaneously (building types 1 and 2)

- Power constraint of the heating device

- Power and availability constraint for charging the EV

- State of charge (SOC) limitation constraints for the EV

The following variable definitions are part of the optimization problem:

- Amount of surplus energy

- Power of RES (wind and PV)

- Peak load

- Difference equation for the temperature of the buffer storage (building types 1 and 2)

- Difference equation for the volume of the hot water tank (building types 1 and 2)

- Difference equation for the energy content of the combined storage (building type 3)

- Difference equation for the SOC of the EV

The coordinating DO approaches of Section 4.2 require the buildings to have not only one schedule but a set of multiple schedules. We use the method introduced in [9] to generate a diverse solution pool that leads to much better results than the conventional procedure of commercial solvers to collect and store the solutions found during the optimization. For this purpose, all buildings have to solve another optimization problem that maximizes the diversity of a new solution to a given optimal schedule. The full commented mathematical representation of the basic problem (described in this section) and the diversity maximization problem (described in [9]) for all three building types can be found at the data repository hosting the supplementary materials for this paper [28]. Moreover, we uploaded the commented code (written in the modeling language GAMS) for all optimization problems used in our study.

\section{Decentralized optimization}

We describe methods for assignment of wind power to buildings in Section 4.1. In Section 4.2, we explain two coordination approaches for decentralized optimization from the literature and introduce a novel approach that is based on the two other ones.

\subsection{Methods for assignment of wind power to decentralized agents}

To assign a central wind power profile to the local optimization problems of different buildings, we propose and investigate two simple methods. Figure 2 illustrates these two methods for the distribution of an entire wind power profile to five buildings. The upper diagram shows an exemplary profile of a small wind turbine that should be distributed to the different buildings such that they can incorporate the generated wind power into their optimization procedures. The left-hand picture depicts the assignment when using the Equal Distribution (ED) method. The entire profile is equally distributed to the five buildings. Eq. (2) shows the formula to calculate the wind power assigned to building $i$. For every time slot $t$, the power value of the entire wind power profile $P_{t}^{\text {Windoverall }}$ is divided by the number of buildings. Thus, each building gets an equal share of wind energy. The buildings include these assigned profiles in their local optimization problems by adding the corresponding values to their PV generation profiles. 


$$
P_{t, i}^{\text {Wind }}=\frac{P_{t}^{\text {Windoverall }}}{\# \text { Buildings }} \quad \forall i \in\{1, \ldots, B\}, \forall t
$$

The picture on the right-hand side of Figure 2 shows the Score-Rank-Proportional Distribution (SRPD) method. In the first step, a score is calculated for every building by using Eq. (3). The power of the building's electric heating device $P_{i}^{\text {ElectricalHeating }}$ and the power for the EV charging station $P_{i}^{\text {EVCharging }}$ are subtracted from the peak power of the PV system $P_{i}^{\text {PVPeak }}$. This score roughly quantifies the expected self-consumption rate of locally generated PV. Buildings that have a high score are more likely to generate surplus energy since their flexible electrical demand might not match their PV generation. As all information from the buildings is static, there is no need to measure any data from the buildings or to monitor demand profiles, which would infringe on the residents' privacy. In the next step, the buildings are ranked according to this score. The building with the highest score gets the highest rank and the building with the lowest score gets the lowest rank. In the example of Figure 2 , building 5 has the lowest score and thus the lowest rank $\left(\operatorname{Rank}_{5}=5\right)$ and building 1 has the highest score and thus the highest rank $\left(\operatorname{Rank}_{1}=1\right)$. SRPD uses Eq. (4) for assignment of the wind power profiles to the buildings. The entire wind power for each time slot is divided by the sum of ranks (in this example, the sum of ranks is $\sum_{i}^{B} \operatorname{Rank}_{i}=1+2+3+4+5=15$ ). This value is then multiplied by the rank of the building which leads to an assignment of more wind power to buildings with lower ranks, as is illustrated in Figure 2. We evaluate the two methods SRPD and ED in Section 5.2.

$$
\begin{aligned}
& \text { Score }_{i}=P_{i}^{\text {PVPeak }}-P_{i}^{\text {ElectricalHeating }}-P_{i}^{\text {EVCharging }} \\
& P_{t, i}^{\text {Wind }}=\frac{P_{t}^{\text {Windoverall }}}{\sum_{i}^{B} \text { Rank }_{i}} \cdot \text { Rank }_{i} \quad \forall i \in\{1, \ldots, B\}, \forall t
\end{aligned}
$$




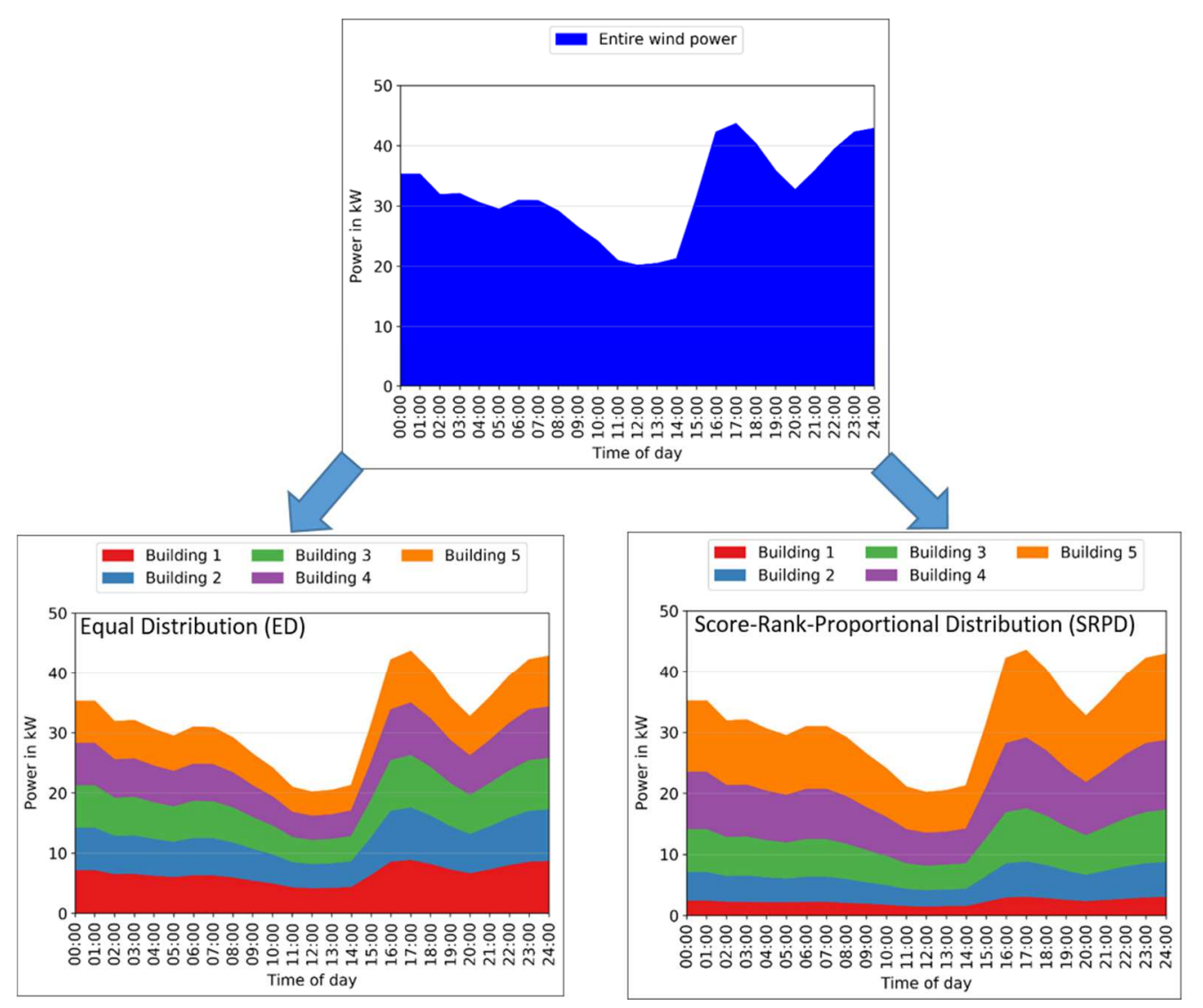

Figure 2: Two methods for assignment of wind power to buildings

\subsection{Coordination methods for decentralized optimization}

\subsubsection{Iterative Desync Algorithm (IDA)}

The Iterative Desync Algorithm (IDA), developed by Kolen et al. [8], is the basic approach for the two other coordinating DO algorithms used in this paper. Figure 3 schematically displays IDA in a residential area. In the first step, all buildings simultaneously create a solution pool that consists of multiple schedules by solving their local optimization problems (see Section 3.2). Afterward, the buildings coordinate the selection of the individual schedules. All buildings are ordered in a cycle and have a predecessor and successor each. Furthermore, the buildings store local views on the residential areas' load profiles (profiles resulting from generation and demand). In each iteration, each building successively selects the schedule out of its solution pool that leads to an optimal value of a common objective. This common objective of our study is based on the load profiles of the residential area. It can be calculated by using the weighted sum of the surplus energy in the residential area, and the peak load (see Eq. (1)). The building then updates the common load profiles of the residential area based on their selected schedules (demand profile) and generation profiles. Next, the building forwards the updated profiles to the next building in the cycle, which performs the same procedure. The algorithm terminates if none of the buildings changes its previously selected schedule for one iteration through the cycle.

To guarantee the privacy-friendliness of this algorithm, the first building to start with this process adds a random noise vector to its load and generation profiles during the first iteration and stores this vector. During the second iteration through the cycle, this building removes the previously added random noise from the load profiles of the residential area. 


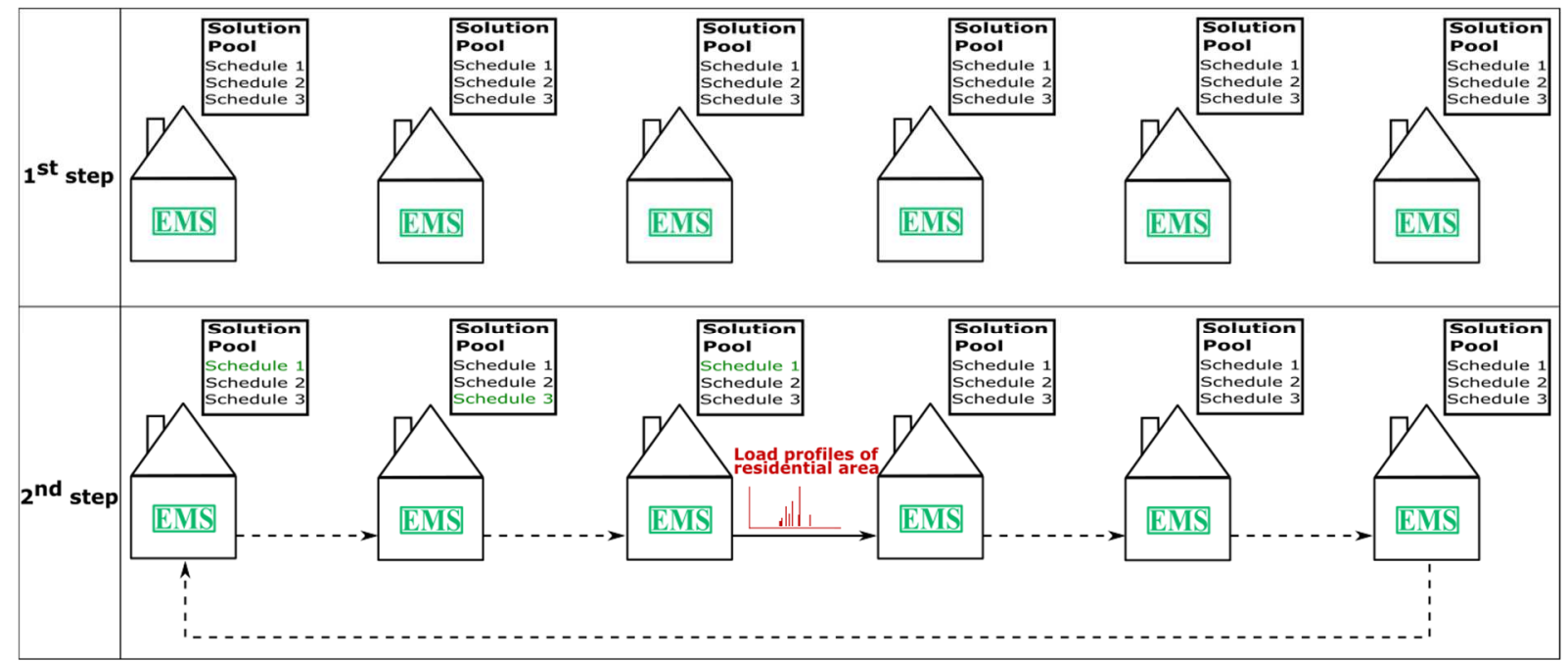

Figure 3: Decentralized optimization approach IDA in a residential area [9]

\subsubsection{Parallel Successive Cluster Optimization with IDA (PSCO-IDA)}

The PSCO-IDA algorithm groups the buildings of the residential area into multiple clusters of a specific size. The number of steps for PSCO-IDA is proportional to the number of buildings in a cluster. Figure 4 shows the algorithm for clusters of size two, as this cluster size led to the best results in our experiments. In the first step, only the first of the two buildings in each cluster solve their local optimization problems in parallel and thus generate a solution pool. Afterward, they forward the resulting surplus power profiles to the next buildings in the clusters, which use these as an input to their local optimization problems. In contrast to IDA, the results of the first buildings' optimization problems directly influence the solution pool of the second buildings in the clusters. In the last step, all buildings of the residential area use IDA to coordinate the selection of the schedules. A more detailed description of IDA and PSCO-IDA can be found in [8, 9].

Instead of randomly assigning buildings to the clusters, we use a simple ordering heuristic that is introduced in [9] and that led to strongly improved results. For each building, a score is calculated by using Eq. (3). The building with the highest score and the building with the lowest score are grouped into the first cluster. For the second cluster, we use the building with the second-highest and the second-lowest score. We successively do this until each building belongs to one cluster. The basic idea behind this clustering is that the buildings with low PV generation can use the surplus power of buildings with high PV generation for their flexible devices as buildings with higher scores tend to generate more surplus energy. 


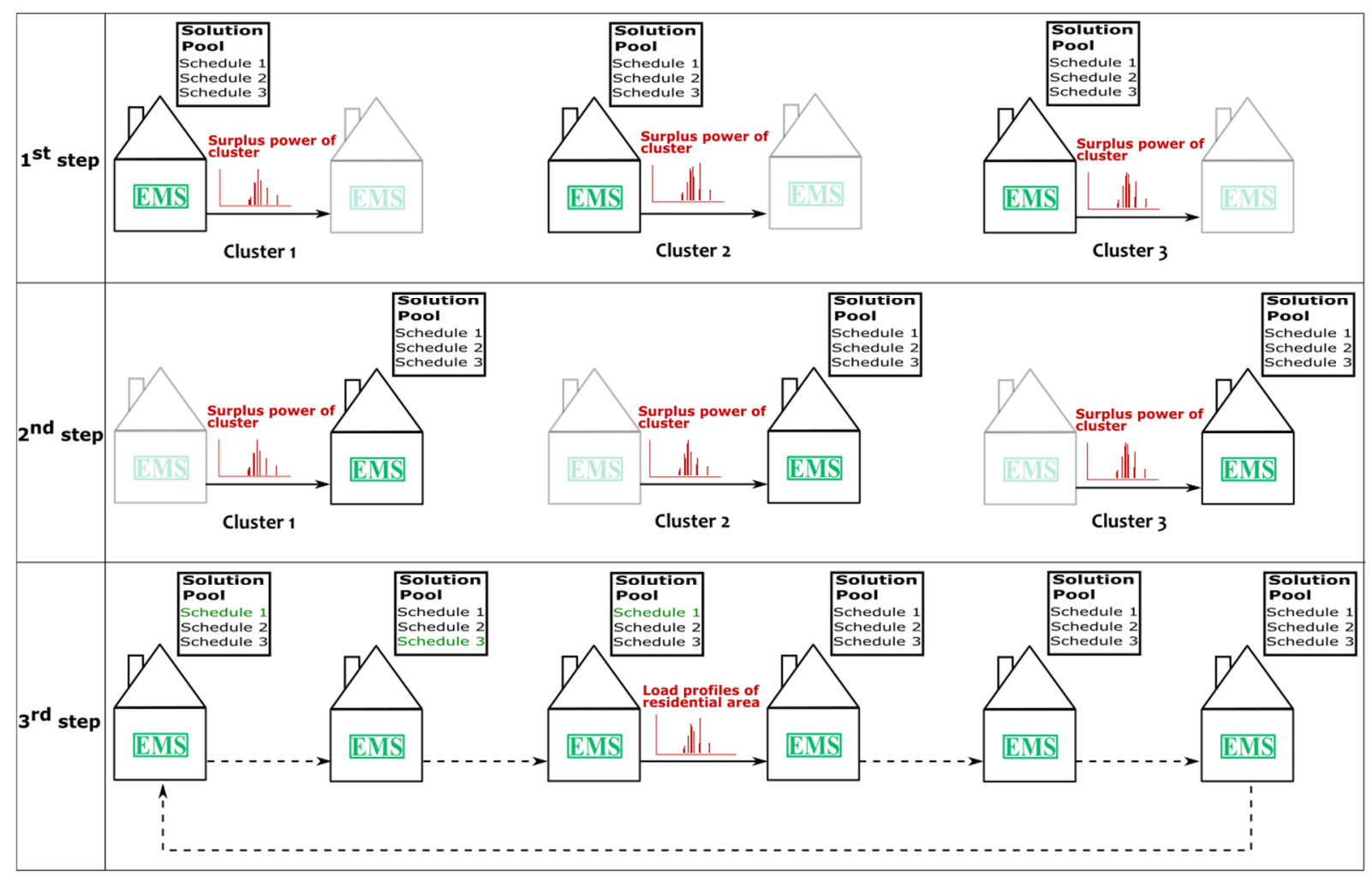

Figure 4: PSCO-IDA algorithm with two buildings per cluster [9]

\subsubsection{Sequential Parallel Cluster Optimization with IDA (SEPACO-IDA)}

The SEPACO-IDA algorithm is one of the two main contributions of this paper. It efficiently combines the PSCO-IDA and IDA algorithms. As in PSCO-IDA, the buildings are divided into an arbitrary number of clusters. In SEPACO-IDA, the number of steps is proportional to the number of clusters. Figure 5 illustrates the algorithm for two clusters. We investigated the algorithm with different numbers of clusters, and two clusters led to the best results while having the lowest computational time. In the first step, the buildings of the first cluster simultaneously generate a solutions pool and use IDA for selecting individual schedules. Afterward, the resulting load profiles of the cluster are sent to all buildings from the second cluster ( $2^{\text {nd }}$ step). Next, the buildings of the second cluster likewise generate a solution pool and use IDA for coordination. The resulting load profiles of the first cluster influence the local optimization problems of the buildings in the second cluster. The surplus power profile of the previous clusters can be assigned to the building of the new cluster by using the methods explained in Section 4.1 for the wind power assignment. In the last step, all buildings of the residential area use IDA to coordinate the selection of the schedules jointly. The difference to PSCO-IDA is that in SEPACO-IDA, the buildings in one cluster generate their solution pool simultaneously and not successively. Moreover, the buildings use IDA for the coordination within every cluster, and optimization of the different clusters is done sequentially and not in parallel. As no building receives direct information from another single building, SEPACO-IDA has a higher level of privacy compared to PSCO-IDA.

We investigated different approaches for assigning buildings to the clusters. The best result was obtained when using the score function of Section 4.1 (Eq. (3)) and putting the buildings with high scores into the first cluster and the buildings with low scores into the second cluster. We also tried a random assignment of buildings to the clusters and assignments based on either an increasing sum of scores per cluster or a similar sum of scores per cluster. However, our approach with a decreasing sum of scores per cluster overall led to the best solutions. We analyze the three DO approaches and compare them to $\mathrm{CO}$ and a conventional control approach in Section 5.3. 


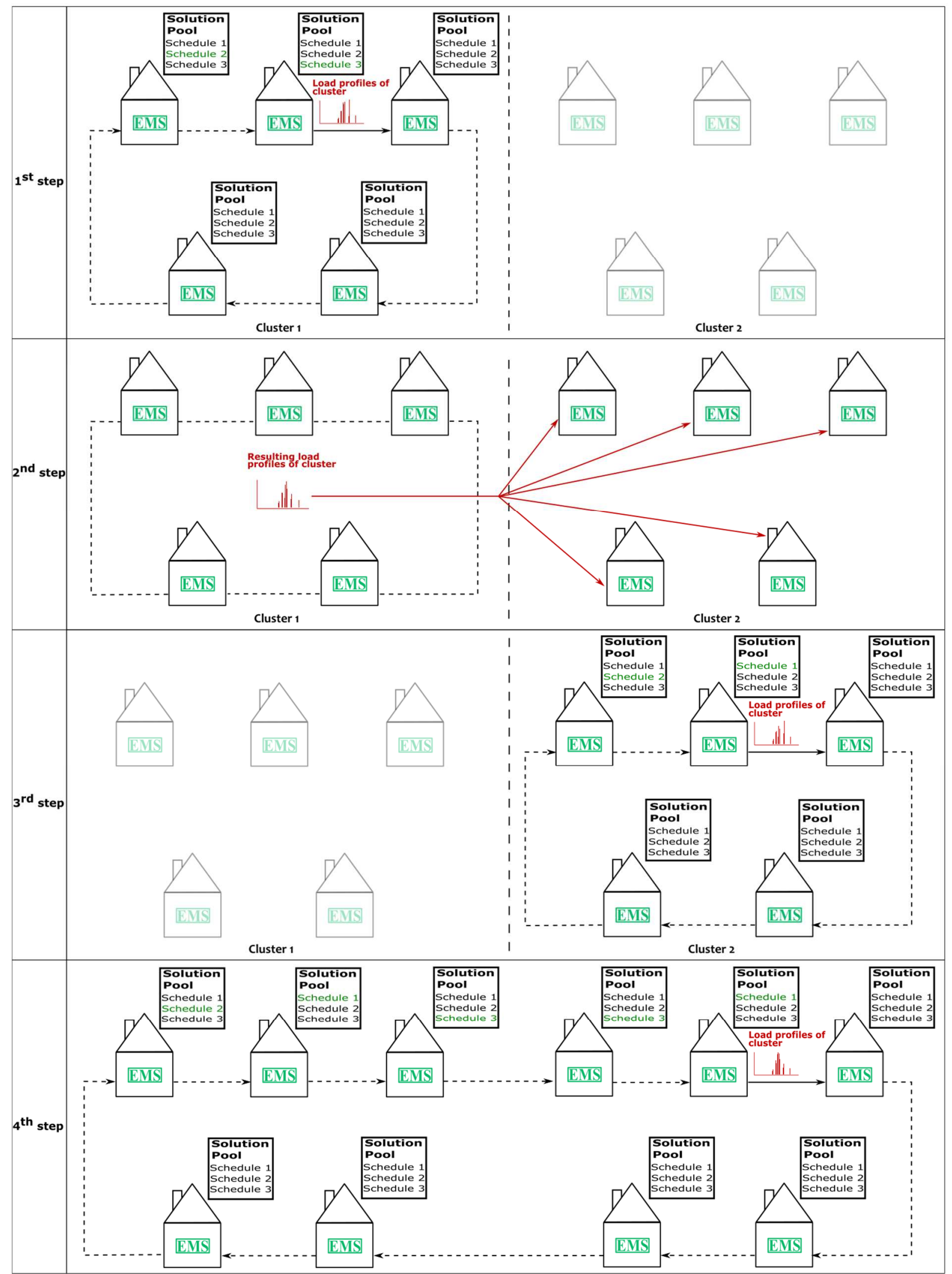

Figure 5: SEPACO-IDA algorithm with two clusters 


\section{Results}

In this section, we evaluate the methods developed in Section 4. Section 5.1 describes the scenarios used for our analysis. In Section 5.2, we compare the two wind assignment methods and in Section 5.3 , we show the results for the different optimization approaches.

\subsection{Scenarios for the analysis}

To analyze the developed methods, we define base case scenarios for 31 days. We randomly choose 31 days with mediocre to high PV or wind energy generation from the heating period in Germany (October - March). In the base case scenarios, we use 15 buildings for each of the three building types, resulting in 45 buildings. Of these, 15 have two residents each, whereas four persons live in each of the other 30 buildings. The average PV peak of buildings which have a PV system on their rooftop is $7 \mathrm{~kW}$ with a maximum positive and negative deviation from the average peak power of $3 \mathrm{~kW}$. This means that the values for the PV systems' peak power of the different buildings are uniformly distributed between $4 \mathrm{~kW}(7-3)$ and $10 \mathrm{~kW}(7+3)$. The share of buildings with a PV system is $50 \%$ in the base case scenarios. Ten of the buildings have an EV that is charged at home. We choose two types of EVs (Opel Ampera-e and BMW i3) and assume that at the beginning of the optimization horizon, the SOC of all vehicles is at 0.5 (50\%). This value is also the target SOC for the end of the optimization horizon. We use the driving and availability patters from [29] as mobility data for the EVs. Table A.1 in the Appendix lists the technical parameters of the EVs and the charging stations. For wind generation, we use profiles of the wind turbine Nordex N27/150 with a capacity of $100 \mathrm{~kW}$ generated by the web tool Renewable.ninja [30].

In addition to the base case scenarios, we generate several further scenarios for our analysis. To this end, we use a Monte Carlo sampling method for the different parameters. Table 1 lists the relevant parameters of the residential area and their average, minimum, and maximum values. For all scenarios, the optimization horizon is one day with a time resolution of five minutes. We implemented the optimization problems in the modeling language GAMS with Cplex as the solver and used Java for the simulations. The solution pool for all coordinating approaches consists of five different solutions, as this leads to a good trade-off between the quality of the results and computational time [9].

Table 1: Parameters for the Monte Carlo sampling

\begin{tabular}{l|c|c|c} 
Parameter & Average & Min & Max \\
\hline Number of buildings type 1 & 15 & 5 & 25 \\
\hline Number of buildings type 2 & 15 & 5 & 25 \\
\hline Number of buildings type 3 & 15 & 5 & 11 \\
\hline PV peak power [kW] & 7 & 3 & 3 \\
\hline $\begin{array}{l}\text { Maximal deviation from PV } \\
\text { peak power [kW] }\end{array}$ & 1.5 & 0 & 75 \\
\hline $\begin{array}{l}\text { Share of buildings with PV } \\
{[\%]}\end{array}$ & 50 & 25 & 21 \\
\hline Number of EVs & 11.5 & 2 & 250
\end{tabular}




\subsection{Wind assignment methods}

For the evaluation of the two different wind assignment methods of Section 4.1, we use six different optimization approaches in combination with the wind assignment methods for the base case scenarios. Figure 6 shows the optimality percentages of the two wind assignment methods for the different optimization approaches averaged over the 31 base case scenarios with wind. Per definition, CO leads to an optimality of $100 \%$. In addition to the three coordination methods for DO described in Section 4.2, we include a conventional control approach (hysteresis control) that is current practice for today's heating systems, and a DO approach without any coordination mechanism in the evaluation. The analysis shows that for $\mathrm{CO}$ and Conventional Control, the two assignment methods ED and SRPD lead to similar results since $\mathrm{CO}$ and Conventional Control do not depend on the assignment of wind power profiles to decentralized entities. The slight difference for Conventional Control occurs because of the random decision on whether to heat up or cool down the thermal storage at the beginning of a day.

For the DO approaches, the application of ED and SRPD leads to different results. While for DO without coordination and for IDA, an equal distribution $(E D)$ of the centralized wind power profile leads to better results, for PSCO-IDA and SEPACO-IDA, the Score-Rank-Proportional Distribution (SRPD) yields better results. This might be explained by the fact that for PSCO-IDA and SEPACO-IDA, a score roughly quantifying the expected self-consumption rate of the different buildings is already used for the generation of the clusters. A second assignment based on such a score might interfere with the notion of the initial clustering. IDA and $D O$ without coordination do not make use of such a score. This might be the reason why consideration of the score brings these optimization approaches closer to optimality, as Figure 6 indicates.

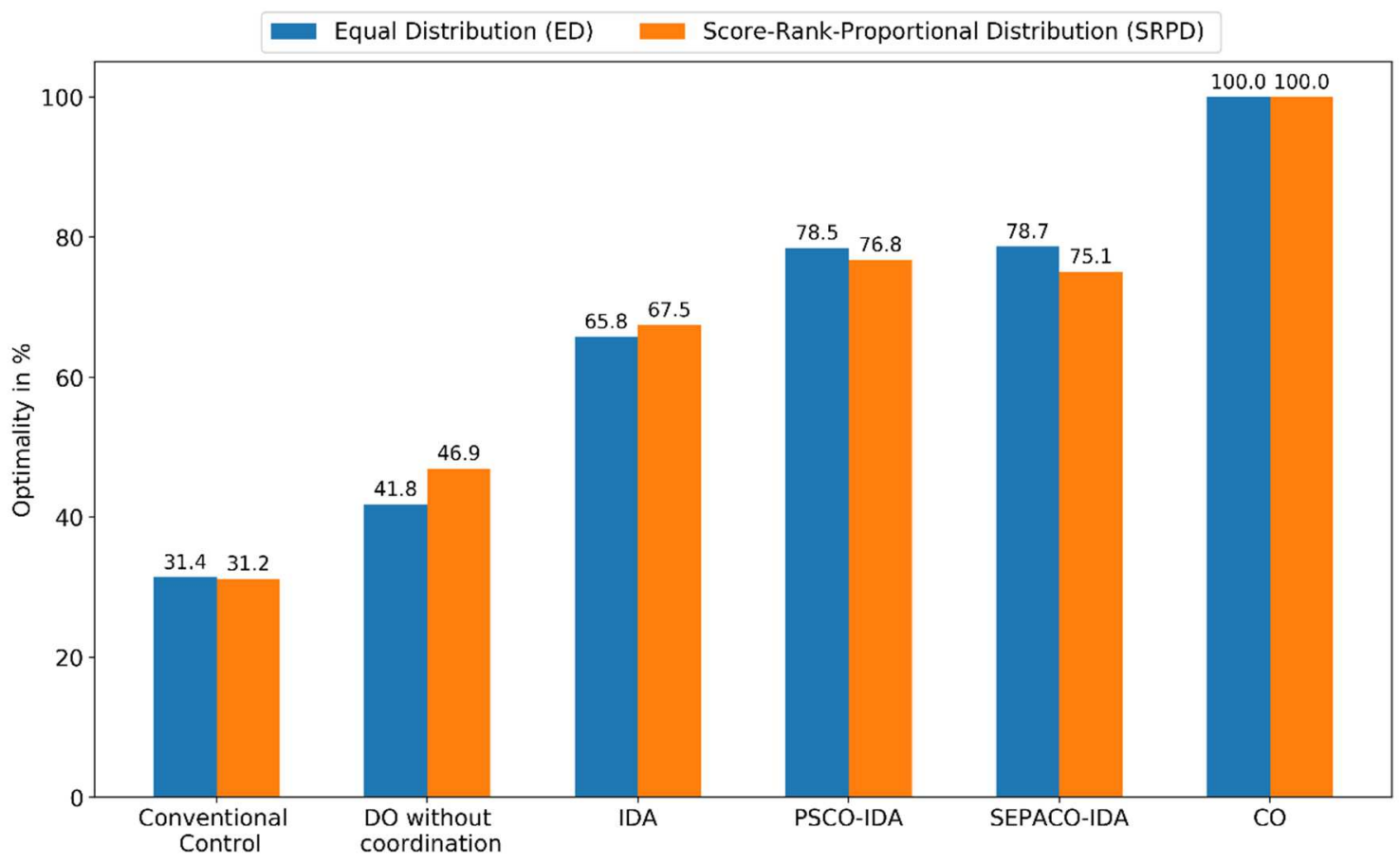

Figure 6: Optimality comparison of the two wind assignment methods for the different optimization approaches averaged over the base case scenarios

\subsection{Optimization approaches}

To compare and evaluate the coordination methods for DO, we use scenarios with and without wind power generation. PV is included in all scenarios. For the scenarios with wind energy generation, we use the 31 days of the base case and generate four additional scenarios per day by using the Monte 
Carlo sampling method. This leads to a total of 155 scenarios. We ran all scenarios with five different combinations of weight coefficients. Figure 7 displays the optimality of the methods used with different weights for the objectives averaged over all scenarios with wind and PV generation. For all weight combinations, Conventional Control, as expected, leads to the worst results having optimality percentages of around $30 \%$. The figure clearly shows that if all buildings only optimize their own goal without interacting with the other buildings, the result is quite far away from the optimal solution. For all weights, DO without coordination leads to optimality percentages below $50 \%$. The results reveal that SEPACO-IDA outperforms the other two coordinating DO approaches IDA and PSCO-IDA having optimality percentages of between $87 \%$ and $79 \%$. The differences to PSCO-IDA are small (between $0.8 \%$ and $2.4 \%$ ), while the improvements compared to IDA are significant (between $11.1 \%$ and $13.3 \%)$. Figure 7 shows that the more the emphasis is on the second goal (reducing the peak load), the worse the results become for all three coordinating DO approaches (IDA, PSCO-IDA, and SEPACOIDA).

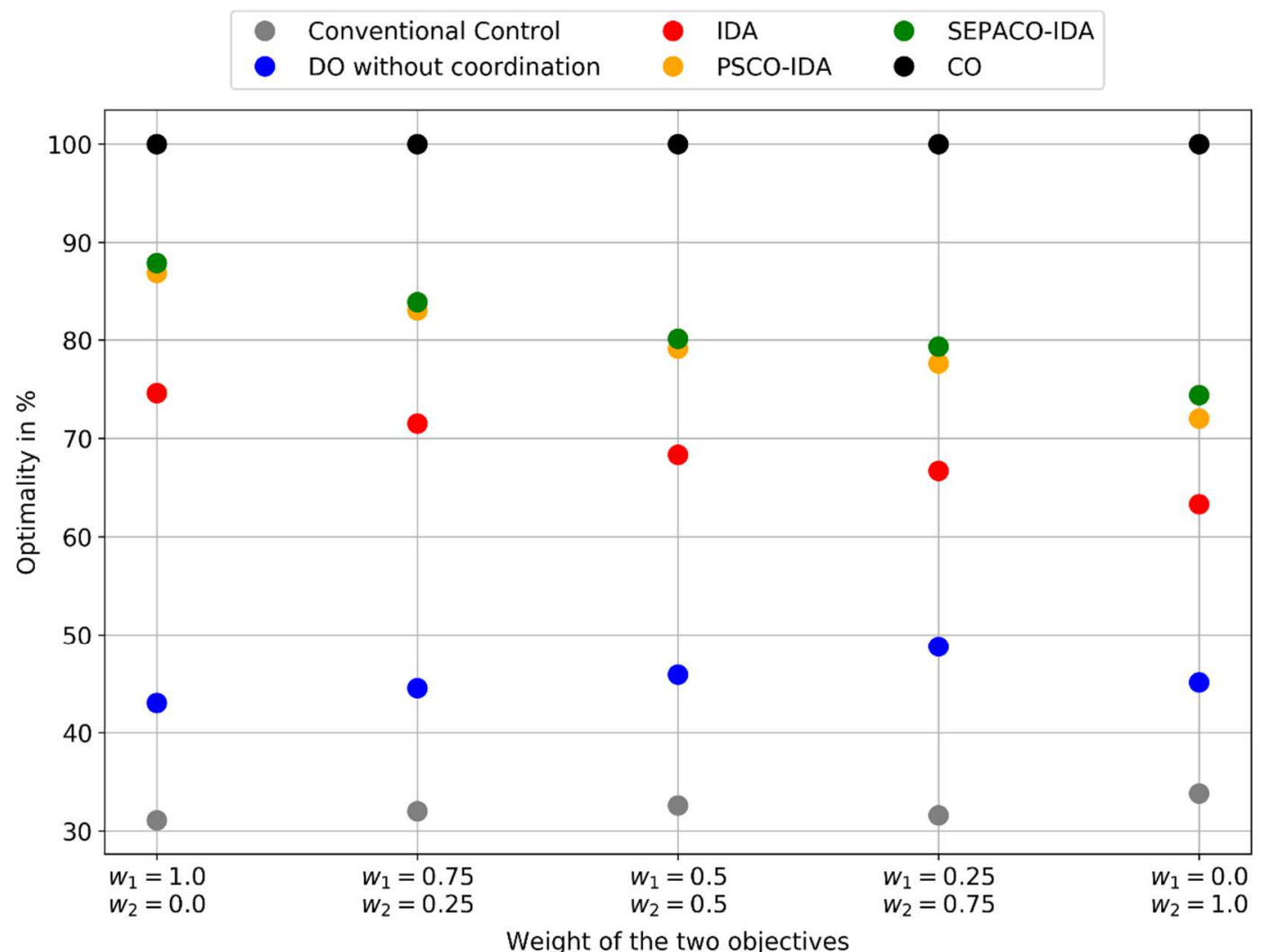

Figure 7: Optimality comparison of the used optimization approaches with different weight combinations for the objectives averaged over all scenarios with wind and PV ( $w_{1}$ : Weight for the Surplus Energy, $w_{2}$ : Weight for the Maximum Load)

Table 2 lists the average results of the scenarios with wind and PV for different weights of the objectives. For Conventional Control, the values of the surplus energy and the maximum load do not depend on the weights of the objectives. For all four DO approaches, the results significantly change for the three weight combinations that have nonzero values for both objectives ( $\left[w_{1}=0.75, w_{2}=0.25\right]$, $\left.\left[w_{1}=0.5, w_{2}=0.5\right],\left[w_{1}=0.25, w_{2}=0.75\right]\right)$. Surprisingly, when putting the whole weight and thus the emphasis only on one objective $\left(\left[w_{1}=1.0, w_{2}=0.0\right]\right.$ or $\left.\left[w_{1}=0.0, w_{2}=1.0\right]\right)$, the results for the single objective are worse than the corresponding result for that objective when also considering the other objective to some degree. This means that decreasing the weight for one objective from 1.0 to 0.75 led to better results for that objective. This counterintuitive outcome can be explained by the 
optimization approach used for creating the solution pool for the DO approaches explained in [9]. A diverse solution pool with different schedules is vital for the DO approaches, as the coordination procedure is not an exact optimization algorithm but a heuristic. Using weights for both objectives leads to higher flexibility for the generation of a solution pool. This eventually can lead to better results for the whole residential area, although the results for the individual buildings might be worse.

For $\mathrm{CO}$, the results among the combined weights ([ $\left.\mathrm{w}_{1}=0.75, \mathrm{w}_{2}=0.25\right],\left[\mathrm{w}_{1}=0.5, \mathrm{w}_{2}=0.5\right],\left[\mathrm{w}_{1}=\right.$ $\left.\left.0.25, w_{2}=0.75\right]\right)$ are almost identical. The results of the objective Maximum Load for the combined weights are equal to the one of the single-objective optimization of the peak load $\left(\left[w_{1}=0.0, w_{2}=1.0\right]\right)$. The results of the objective Surplus Energy are only slightly worse for the combined objectives compared to the single-objective optimization $\left(\left[w_{1}=1.0, w_{2}=0.0\right]\right)$. This indicates that the objectives in our case studies are not contrary to each other. The surplus energy can simultaneously be minimized with the maximum load because the power of the RES mainly causes the peak load. However, if the full focus is on one objective only, the other objective is neglected, which leads to very poor results for that objective. This is valid for CO and all DO approaches. Thus, for scenarios with high power generation by RES in residential areas where the peak load at the transformer is mainly caused by feeding power of RES from the local grid into the whole grid, the consideration of a combined objective function is highly beneficial.

Table 2: Average results of the scenarios with wind and PV for different weight combinations of the objectives (Surplus Energy in $\mathrm{kWh}$ and Maximum Load in $\mathrm{kW}$ )

\begin{tabular}{c|c|c|c|c|c|c} 
Objectives & $\begin{array}{c}\text { Conventional } \\
\text { Control }\end{array}$ & $\begin{array}{c}\text { DO with no } \\
\text { coordination }\end{array}$ & IDA & $\begin{array}{c}\text { PSCO- } \\
\text { IDA }\end{array}$ & $\begin{array}{c}\text { SEPACO- } \\
\text { IDA }\end{array}$ & CO \\
\hline $\begin{array}{c}\text { Surplus Energy } \\
\text { (Weight } w_{1}=1.0 \text { ) }\end{array}$ & 666.8 & 481.8 & 278.0 & 238.7 & 236.0 & 207.7 \\
\hline $\begin{array}{c}\text { Maximum Load } \\
\left.\text { (Weight } w_{2}=0.0\right)\end{array}$ & 111.4 & 93.2 & 77.1 & 72.6 & 72.5 & 75.0 \\
\hline $\begin{array}{c}\text { Surplus Energy } \\
\left.\text { (Weight } w_{1}=0.75\right)\end{array}$ & 666.8 & 475.6 & 276.8 & 236.8 & 234.1 & 210.3 \\
\hline $\begin{array}{c}\text { Maximum Load } \\
\left.\text { (Weight } w_{2}=0.25\right)\end{array}$ & 111.4 & 82.4 & 64.3 & 56.9 & 56.7 & 37.6 \\
\hline $\begin{array}{c}\text { Surplus Energy } \\
\left.\text { (Weight } w_{1}=0.5\right)\end{array}$ & 666.8 & 477.8 & 279.5 & 238.6 & 237.1 & 210.3 \\
\hline $\begin{array}{c}\text { Maximum Load } \\
\left.\text { (Weight } w_{2}=0.5\right)\end{array}$ & 111.4 & 78.2 & 60.9 & 53.5 & 52.4 & 37.5 \\
\hline $\begin{array}{c}\text { Surplus Energy } \\
\left.\text { (Weight } w_{1}=0.25\right)\end{array}$ & 666.8 & 477.8 & 283.2 & 239.7 & 239.6 & 210.4 \\
\hline $\begin{array}{c}\text { Maximum Load } \\
\left.\text { (Weight } w_{2}=0.75\right)\end{array}$ & 111.4 & 75.7 & 58.4 & 50.5 & 49.1 & 37.5 \\
\hline $\begin{array}{c}\text { Surplus Energy } \\
\text { (Weight } w_{1}=0.0 \text { ) }\end{array}$ & 666.8 & 637.4 & 361.4 & 341.0 & 343.2 & 370.1 \\
\hline $\begin{array}{c}\text { Maximum Load } \\
\left.\text { (Weight } w_{2}=1.0\right)\end{array}$ & 111.4 & 83.1 & 59.3 & 52.1 & 50.4 & 37.5
\end{tabular}

As the authors of [9] only test the algorithm PSCO-IDA in scenarios with PV, but without wind energy, we also evaluate the newly developed algorithm SEPACO-IDA in scenarios without wind. Figure 8 illustrates the optimality percentages of the used control approaches with different weights for the objectives averaged over all scenarios with PV and no wind. For this purpose, we used the base case scenarios without wind and additionally generated three scenarios for each day, leading to a total of 
124 scenarios. The results show that SEPACO-IDA again leads to better results compared to IDA and PSCO-IDA (for the combined weights [ $\mathrm{w}_{1}=0.25, \mathrm{w}_{2}=0.75$ ], PSCO-IDA and SEPACO-IDA have similar results). The optimality percentages of PSCO-IDA and SEPACO-IDA do not vary strongly for the different weight combinations. In contrast, the difference to IDA becomes smaller with an increasing emphasis on the objective of minimizing the peak load.

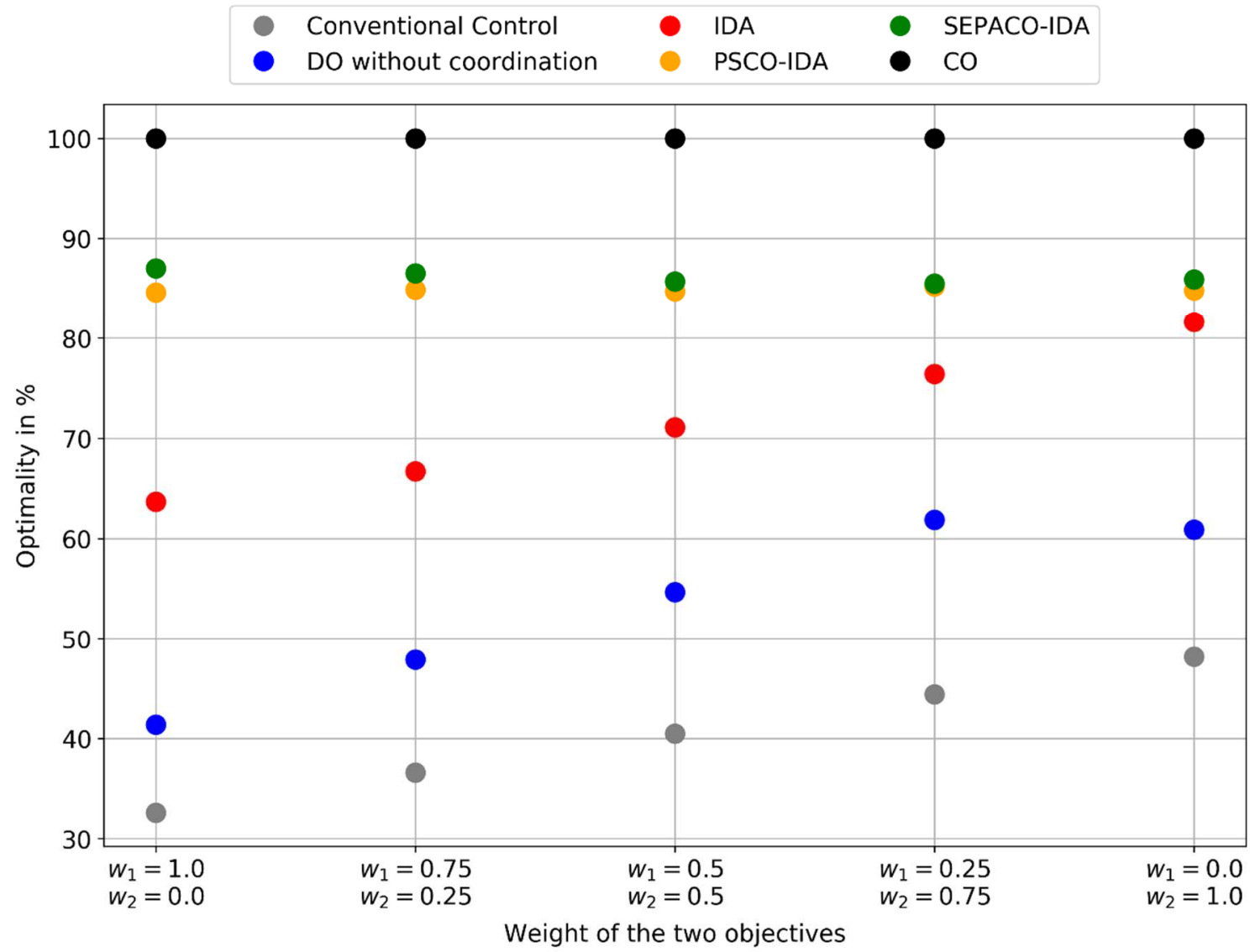

Figure 8: Optimality comparison of the used optimization approaches with different weight combinations for the objectives averaged over all scenarios with PV and no wind ( $w_{1}$ : Weight for the Surplus Energy, $w_{2}$ : Weight for the Maximum Load)

Table 3 shows the average runtimes and number of coordination rounds of the optimization approaches for the base case scenarios with wind and PV. CO has the highest runtime requiring around 20 times more time than SEPACO-IDA. We used an Intel i7 $3930 \mathrm{~K}$ system with $3.2 \mathrm{GHz}$ and 64 GB RAM for the analysis. The MIP gap for both the centralized and the decentralized optimization problems was set to $0.1 \%$. Surprisingly, SEPACO-IDA led to a similar number of coordination rounds for selection of the schedules as IDA and fewer coordination rounds compared to PSCO-IDA. Although SEPACO-IDA needs coordination for each cluster, the final IDA step converges rather quickly. We included the load profiles of all buildings for all base case scenarios to the uploaded supplementary materials of this paper [28]. Moreover, we added result tables, which include detailed information about the results and the configurations of every single scenario to the supplementary materials. 


\begin{tabular}{l|c|c}
\multicolumn{1}{c|}{ Approach } & Runtime [s] & $\begin{array}{c}\text { Number of } \\
\text { coordination } \\
\text { rounds }\end{array}$ \\
\hline Conventional Control & 2 & - \\
\hline DO without coordination & 13 & - \\
\hline IDA & 47 & 4.7 \\
\hline PSCO-IDA & 76 & 4.9 \\
\hline SEPACO-IDA & 86 & 4.7 \\
\hline CO & 1770 & -
\end{tabular}

\subsection{Critical appraisal}

For our study, we made some simplifications. We assumed perfect foresight regarding the generation and demand of the buildings for all optimization problems. To apply the investigated methods to realworld scenarios, they have to be combined with forecasts and uncertainty handling methods for scheduling-based optimization like [31, 32]. Furthermore, we assumed that all buildings agree to participate in the decentralized optimization without any incentive. The focus of this study was to investigate different optimization approaches from a system perspective and not to analyze market strategies for incentivizing building owners to use their flexibility or to trade their generated electricity locally.

We merely tested two different methods for wind power assignment. Many other possible criteria for the assignment of wind power profiles to the local optimization problems of decentralized entities exist. Also, for the coordination approach SEPACO-IDA, clustering methods based on other score functions or ranking schemes have not been analyzed in detail. Doing a large-scale analysis of different methods for generating the clusters could even improve SEPACO-IDA.

\section{Summary and conclusion}

In this paper, we developed a novel coordination mechanism for optimally using flexible electrical loads in a decentralized way in order to react to the volatile supply from renewable energy sources in a residential area. The Sequential Parallel Cluster Optimization with IDA (SEPACO-IDA) combines two coordination algorithms from the literature for decentralized optimization that are based on a set of schedules (PSCO-IDA and IDA). In a case study that consists of a high number of scenarios, we compared our developed approach to existing approaches for decentralized optimization, to a conventional control approach and a centralized optimization. The load flexibility in the residential areas comes from electric heating devices and electric vehicles. The results reveal the superiority of SEPACO-IDA over the other coordinating approaches for decentralized optimization. Further, our analysis demonstrates that uncoordinated decentralized optimization leads to fairly bad results. In addition to that, we investigated the two methods Equal Distribution and Score-Rank-Proportional Distribution for assigning a wind power profile to the local optimization problems of decentralized agents. These methods are used in combination with decentralized optimization approaches. While for the uncoordinated decentralized optimization and IDA, the wind assignment method Score-RankProportional Distribution yields better results, the two decentralized optimization approaches SEPACOIDA and PSCO-IDA profit more from the Equal Distribution method. 
All introduced methods are easy to implement and preserve the privacy of the residents. Our study shows the suboptimality of the currently used conventional control approaches and the crucial advantages of coordinating decentralized optimization. Sustainable energy systems with high shares of renewable energy sources can profit from the application of the developed methods. They can help to overcome the challenges brought about by the weather-dependent electricity generation of wind turbines and photovoltaic systems.

Future work could compare the used scheduling-based decentralized optimization approaches to rulebased or to machine-learning-based control approaches. Moreover, different criteria (like the sum of the total electricity consumption) for the assignment of wind power profiles to decentralized optimization problems of buildings should be investigated. Designing novel market mechanisms to offer incentives to building owners to participate in demand response programs is an essential task for exploiting the load flexibilities in residential areas and should be analyzed in future work.

\section{Supplementary materials}

We added the following supplementary materials to an open-source online data repository [28] hosted at Mendeley Data (https://data.mendeley.com/datasets/8jx97kfjxg/2):

- Full mathematical description of all optimization problems with explanations of the equations

- Resulting load and temperature profiles of the buildings for the base case scenarios

- Result tables with detailed information about the scenarios and their results

- Commented code (in the modeling language GAMS) of the decentralized optimization problems for the different building types and the centralized optimization problem

\section{Acknowledgments}

This work was supported by the Research Training Group 2153 of Deutsche Forschungsgemeinschaft (DFG): "Energy Status Data - Informatics Methods for its Collection, Analysis and Exploitation." The authors want to thank Zongfei Wang for providing the mobility data of the electric vehicles. 


\section{Appendix}

\section{Parameters of the residential area}

Table A.1: Parameters of the residential area

\begin{tabular}{|c|c|c|c|}
\hline Parameter & Value & Source & Comment \\
\hline Heated area of the buildings & $140 \mathrm{~m}^{2}$ & [33] & $\begin{array}{l}\text { Assumption: Not all rooms } \\
\text { in the cellar are heated }\end{array}$ \\
\hline $\begin{array}{l}\text { Concrete width (for the } \\
\text { underfloor heating system) }\end{array}$ & $7 \mathrm{~cm}$ & [34] & $\begin{array}{l}\text { DIN standard } 18560 \text { for } \\
\text { screeds in building } \\
\text { construction }\end{array}$ \\
\hline Density of concrete & $2400 \frac{\mathrm{kg}}{\mathrm{m}^{3}}$ & [35] & $\begin{array}{l}\text { European standards for } \\
\text { concrete EN 206-1 }\end{array}$ \\
\hline Heat capacity of concrete & $1000 \frac{\mathrm{J}}{\mathrm{kg} \cdot \mathrm{K}}$ & [35] & $\begin{array}{l}\text { European standards for } \\
\text { concrete EN 206-1 }\end{array}$ \\
\hline $\begin{array}{l}\text { Temperature range of the } \\
\text { underfloor heating system }\end{array}$ & $20-22^{\circ} \mathrm{C}$ & [36] & $\begin{array}{l}\text { Assumptions for optimal } \\
\text { comfort }\end{array}$ \\
\hline $\begin{array}{l}\text { Temperature range of the } \\
\text { hot water tank (buffer } \\
\text { storage) }\end{array}$ & $30-45^{\circ} \mathrm{C}$ & [37] & \\
\hline DHW tank volume & $150 \mathrm{I}, 200 \mathrm{I}$ & [38] & $\begin{array}{c}200 \text { I for } 4 \text { residents, } 150 \text { I } \\
\text { for } 2\end{array}$ \\
\hline Losses of space heating & $45 \mathrm{~W}$ & & Assumption \\
\hline Losses of DHW tank & $35 \mathrm{~W}$ & [39] & $\begin{array}{l}2^{\text {nd }} \text { highest efficiency class } \\
\text { (EU regulations 814/2013) }\end{array}$ \\
\hline $\begin{array}{l}\text { Supply temperature of the } \\
\text { underfloor heating system }\end{array}$ & $30^{\circ} \mathrm{C}$ & [36] & \\
\hline $\begin{array}{l}\text { Supply temperature of the } \\
\text { hot water tank (buffer } \\
\text { storage) }\end{array}$ & $60^{\circ} \mathrm{C}$ & [37] & \\
\hline $\begin{array}{l}\text { Supply temperature of the } \\
\text { hot water tank (DHW) }\end{array}$ & $45^{\circ} \mathrm{C}$ & [41] & \\
\hline $\begin{array}{l}\text { Energy content of the } \\
\text { combined storage }\end{array}$ & $14 \mathrm{kWh}$ & & \\
\hline $\begin{array}{l}\text { Electrical power of the } \\
\text { heating devices }\end{array}$ & $\begin{array}{c}1.2 \mathrm{~kW} \text { (BT 1), } 3 \mathrm{~kW} \\
\text { (BT 2, BT 3) }\end{array}$ & & $\begin{array}{c}\text { Thermal power of the gas } \\
\text { heating device: } 12 \mathrm{~kW}\end{array}$ \\
\hline $\begin{array}{l}\text { COP of the air-source heat } \\
\text { pump for } \Delta T=28 \mathrm{~K}\end{array}$ & 3.8 & [40] & $\begin{array}{l}\text { Similar value as model } L A \\
\text { 28TBS from Glen Dimplex }\end{array}$ \\
\hline $\begin{array}{l}\text { COP of the air-source heat } \\
\text { pump for } \Delta T=42 \mathrm{~K}\end{array}$ & 2.8 & [40] & $\begin{array}{l}\text { Similar value as model LA } \\
\text { 28TBS from Glen Dimplex }\end{array}$ \\
\hline $\begin{array}{l}\text { COP of the ground-source } \\
\text { heat pump for } \Delta T=35 \mathrm{~K}\end{array}$ & 4.7 & [42] & $\begin{array}{c}\text { Similar value as model SIK } \\
\text { 6TES from Glen Dimplex }\end{array}$ \\
\hline $\begin{array}{l}\text { COP of the ground-source } \\
\text { heat pump for } \Delta T=45 \mathrm{~K}\end{array}$ & 3.7 & [42] & $\begin{array}{c}\text { Similar value as model SIK } \\
\text { 6TES from Glen Dimplex }\end{array}$ \\
\hline Battery capacity BMW i3 & $37.9 \mathrm{kWh}$ & [43] & \\
\hline Charging efficiency $B M W$ i3 & $85 \%$ & [43] & \\
\hline $\begin{array}{l}\text { Energy consumption per } \\
100 \mathrm{~km} \mathrm{BMW} \mathrm{i3}\end{array}$ & $13.9 \mathrm{kWh}$ & [43] & \\
\hline $\begin{array}{l}\text { Battery capacity } \\
\text { Opel Ampera-e }\end{array}$ & $60 \mathrm{kWh}$ & [43] & \\
\hline $\begin{array}{l}\text { Charging efficiency } \\
\text { Opel Ampera-e }\end{array}$ & $89 \%$ & [43] & \\
\hline
\end{tabular}




\begin{tabular}{l|c|c|c} 
Parameter & Value & Source & Comment \\
\hline $\begin{array}{l}\text { Energy consumption per } \\
100 \mathrm{~km} \text { Opel Ampera-e }\end{array}$ & $17.5 \mathrm{kWh}$ & {$[43]$} & \\
\hline $\begin{array}{l}\text { Maximal charging power for } \\
\text { home charging }\end{array}$ & $4.6 \mathrm{~kW}$ & {$[44]$} & Wallbox: KEBA KeContact \\
P30
\end{tabular}

\section{References}

[1] Shariatzadeh F, Mandal P, Srivastava AK (2015): Demand response for sustainable energy systems: A review, application and implementation strategy. Renewable and Sustainable Energy Reviews 45: 343-350. doi: 10.1016/j.rser.2015.01.062

[2] Shao S, Pipattanasomporn M, Rahman S (2011): Demand Response as a Load Shaping Tool in an Intelligent Grid With Electric Vehicles. IEEE Trans. Smart Grid 2(4): 624-631. doi: 10.1109/TSG.2011.2164583

[3] Patteeuw D, Bruninx K, Arteconi A et al. (2015): Integrated modeling of active demand response with electric heating systems coupled to thermal energy storage systems. Applied Energy 151: 306-319. doi: 10.1016/j.apenergy.2015.04.014

[4] Narayanan A, Mets K, Strobbe M et al. (2019): Feasibility of $100 \%$ renewable energybased electricity production for cities with storage and flexibility. Renewable Energy 134: 698-709. doi: 10.1016/j.renene.2018.11.049

[5] Dileep G (2020): A survey on smart grid technologies and applications. Renewable Energy 146: 2589-2625. doi: 10.1016/j.renene.2019.08.092

[6] Bundesnetzagentur (2019): Quartalsbericht zu Netz- und Systemsicherheitsmaßnahmen - Gesamtjahr und Viertes Quartal 2018

[7] Jordehi AR (2019): Optimisation of demand response in electric power systems, a review. Renewable and Sustainable Energy Reviews 103: 308-319. doi: 10.1016/j.rser.2018.12.054

[8] Kolen S, Molitor C, Wagner L et al. (2017): Two-level agent-based scheduling for a cluster of heating systems. Sustainable Cities and Society 30: 273-281. doi: 10.1016/j.scs.2017.01.014

[9] Dengiz T, Jochem P (2020): Decentralized optimization approaches for using the load flexibility of electric heating devices. Energy 193: 116651. doi: 10.1016/j.energy.2019.116651

[10] Ullman JD (1975): NP-complete scheduling problems. Journal of Computer and System Sciences 10(3): 384-393. doi: 10.1016/S0022-0000(75)80008-0

[11] Guo F, Wen C, Mao J et al. (2016): Distributed Economic Dispatch for Smart Grids With Random Wind Power. IEEE Trans. Smart Grid 7(3): 1572-1583. doi: 10.1109/TSG.2015.2434831

[12] Braun P, Grune L, Kellett CM et al. (2015): Predictive control of a Smart Grid: A distributed optimization algorithm with centralized performance properties. In: Control ICoDa (ed) 2015 54th IEEE Conference on Decision and Control (CDC): Date: 15-18 Dec. 2015. IEEE, [Piscataway, NJ], pp 5593-5598

[13] Harb H, Paprott J-N, Matthes P et al. (2015): Decentralized scheduling strategy of heating systems for balancing the residual load. Building and Environment 86: 132-140. doi: 10.1016/j.buildenv.2014.12.015

[14] Liu Y, Yu N, Wang W et al. (2018): Coordinating the operations of smart buildings in smart grids. Applied Energy 228: 2510-2525. doi: 10.1016/j.apenergy.2018.07.089 
[15] Diekerhof M, Schwarz S, Martin F et al. (2018): Distributed Optimization for Scheduling Electrical Demand in Complex City Districts. IEEE Systems Journal 12(4): 3226-3237. doi: 10.1109/JSYST.2017.2713798

[16] Worthmann K, Kellett CM, Braun P et al. (2015): Distributed and Decentralized Control of Residential Energy Systems Incorporating Battery Storage. IEEE Trans. Smart Grid 6(4): 1914-1923. doi: 10.1109/TSG.2015.2392081

[17] Menon RP, Amblard F, Page J (2019): Distributed Model Predictive Control For Demand Response On Thermal Devices in Building Blocks. In: 2019 IEEE PES Innovative Smart Grid Technologies Europe (ISGT-Europe), pp 1-5

[18] Sarvapali D. Ramchurn, Perukrishnen Vytelingum, Alex Rogers et al.: Agent-based control for decentralised demand side management in the smart grid. In: The Tenth International Conference on Autonomous Agents and Multiagent Systems (AAMAS 2011), Taiwan, Province of China. 02 - 06 May 2011. pp. 5-12 .

[19] Chang T-H, Nedic A, Scaglione A (2014): Distributed Constrained Optimization by Consensus-Based Primal-Dual Perturbation Method. IEEE Trans. Automat. Contr. 59(6): 1524-1538. doi: 10.1109/TAC.2014.2308612

[20] Ogston E, Zeman A, Prokopenko M et al. (2007): Clustering Distributed Energy Resources for Large-Scale Demand Management. In: Di Marzo Serugendo G (ed) First International Conference on Self-Adaptive and Self-Organizing Systems, 2007: SASO '07 ; 9 - 11 July 2007, Cambridge, Massachusetts ; proceedings. IEEE Computer Society, Los Alamitos, Calif. [u.a.], pp 97-108

[21] Blaauwbroek N, Nguyen PH, Konsman MJ et al. (2015): Decentralized Resource Allocation and Load Scheduling for Multicommodity Smart Energy Systems. IEEE Trans. Sustain. Energy 6(4): 1506-1514. doi: 10.1109/TSTE.2015.2441107

[22] Ghasemi A, Mortazavi SS, Mashhour E (2016): Hourly demand response and battery energy storage for imbalance reduction of smart distribution company embedded with electric vehicles and wind farms. Renewable Energy 85: 124-136. doi: 10.1016/j.renene.2015.06.018

[23] Zhao L, Zeng B (2012 - 2012): Robust unit commitment problem with demand response and wind energy. In: 2012 IEEE Power and Energy Society General Meeting. IEEE, pp 1-8

[24] Shao C, Ding Y, Siano P et al. (2019): A Framework for Incorporating Demand Response of Smart Buildings Into the Integrated Heat and Electricity Energy System. IEEE Trans. Ind. Electron. 66(2): 1465-1475. doi: 10.1109/TIE.2017.2784393

[25] Jiang Y, Xu J, Sun Y et al. (2017): Day-ahead stochastic economic dispatch of wind integrated power system considering demand response of residential hybrid energy system. Applied Energy 190: 1126-1137. doi: 10.1016/j.apenergy.2017.01.030

[26] Fischer D, Härtl A, Wille-Haussmann B (2015): Model for electric load profiles with high time resolution for German households. Energy and Buildings 92: 170-179. doi: 10.1016/j.enbuild.2015.01.058

[27] Grodzevich O, Romanko O (2006): Normalization and Other Topics in Multi -Objective Optimization. Proceedings of the Fields-MITACS Industrial Problems Workshop 2006

[28] Dengiz T (2020): Supplementary materials for paper "Demand response through decentralized optimization in residential areas with wind and photovoltaics". https://data.mendeley.com/datasets/8jx97kfjxg/2

[29] Wang Z, Jochem P, Fichtner W (2020): A scenario-based stochastic optimization model for charging scheduling of electric vehicles under uncertainties of vehicle availability and charging demand. Journal of Cleaner Production 254: 119886. doi: 10.1016/j.jclepro.2019.119886

[30] Staffell I, Pfenninger S (2016): Using bias-corrected reanalysis to simulate current and future wind power output. Energy 114: 1224-1239. doi: 10.1016/j.energy.2016.08.068

[31] Dengiz T, Jochem P, Fichtner W (2019 - 2019): Uncertainty handling control algorithms for demand response with modulating electric heating devices. In: 2019 IEEE PES Innovative Smart Grid Technologies Europe (ISGT-Europe). IEEE, pp 1-5 
[32] Mazidi M, Rezaei N, Ghaderi A (2019): Simultaneous power and heat scheduling of microgrids considering operational uncertainties: A new stochastic $p$-robust optimization approach. Energy 185: 239-253. doi: 10.1016/j.energy.2019.07.046

[33] Fraunhofer-Institut für Solare Energiesysteme ISE: synPRO. https://www.elink.tools/elink-tools/synpro. Accessed 20 Aug 2018

[34] DIN 18560-2:2009-09, Estriche im Bauwesen_-Teil_2: Estriche und Heizestriche auf Dämmschichten (schwimmende Estriche)

[35] IBU - Institut Bauen und Umwelt e.V (2013): Beton der Druckfestigkeitsklasse C 20/25. https://www.beton.org/fileadmin/betonorg/media/Wissen/Nachhaltigkeit/EPD_IZB_2013411_C20_25_D.pdf. Accessed 19 Aug 2018

[36] The Danfoss Group (2008): Handbook Hydronic Floor Heating. http://heating.danfoss.com/PCMPDF/Handbook_Introduction_VGDYA102_lo-res.pdf. Accessed 11 Nov 2018

[37] Institut für Technische Gebäudeausrüstung Dresden (2014): Energetische Bewertung einer Wärme- und Warmwasserversorgung mit Wohnungsstationen im Vergleich mit einem konventionellen zentralen bzw. dezentralen System. https://www.oventrop.com/Pools/Files/file/de/Energetische_Bewertung_Wohnungssta tionen_11671645-aca2-4065-85d6-8994235daae9.pdf. Accessed 18 Mar 2019

[38] Viessmann Deutschland GmbH (2011): Planungshandbuch Wärmepumpen. https://www.viessmann.de/content/dam/vi-brands/DE/PDF/Planungshandbuch/phwaermepumpen.pdf/_jcr_content/renditions/original.media_file.download_attachmen t.file/ph-waermepumpen.pdf. Accessed 19 Aug 2018

[39] Umweltbundesamt (2013): Ökodesign - Richtlinie und Energieverbrauchskennzeichnung - Warmwasserbereiter und Warmwasserspeicher. https://www.umweltbundesamt.de/sites/default/files/medien/376/dokumente/oekod esignrichtlinie_und_energieverbrauchskennzeichnung_warmwasserbereiter.pdf. Accessed 19 Aug 2018

[40] Glen Dimplex Deutschland GmbH: LA 28TBS. http://www.dimplex.de/waermepumpe/luft-wasser/aussenaufstellung/la-28tbs.html. Accessed 18 Mar 2019

[41] Paulsen O, Fan J, Furbo S et al. (2008): Consumer Unit for Low Energy District Heating Net. Proceedings of The 11th International Symposium on District Heating and Cooling

[42] Glen Dimplex Deutschland GmbH: SIK 6TES. http://www.dimplex.de/waermepumpe/sole-wasser-erdwaerme/kompakt-fuereinfache-und-schnelle-installation/sik-6tes.html. Accessed 18 Mar 2019

[43] ADAC e.V. (2020): Aktuelle Elektroautos im Test: So hoch ist der Stromverbrauch. https://www.adac.de/rund-ums-fahrzeug/tests/elektromobilitaet/stromverbrauchelektroautos-adac-test/

[44] ADAC e.V. (2020): ADAC Test Wallboxen 2018/19: KEBA KeContact P30. https://www.adac.de/rund-umsfahrzeug/tests/elektromobilitaet/wallboxen/details/4180/keba-kecontact-p30/

[45] Federal Ministry of Transport and Digital Infrastructure (2018): Mobilität in Deutschland - MiD. https://www.bmvi.de/SharedDocs/DE/Anlage/G/midergebnisbericht.pdf?_blob=publicationFile. Accessed 17 Jan 2020 


\title{
Working Paper Series in Production and Energy
}

\author{
recent issues
}

No. 41 Jann Weinand, Fabian Scheller, Russell McKenna: Reviewing energy system modelling of decentralized energy autonomy

No. 40 Jann Weinand, Sabrina Ried, Max Kleinebrahm, Russell McKenna, Wolf Fichtner: Identification of potential off-grid municipalities with $100 \%$ renewable energy supply

No. 39 Rebekka Volk, Christian Kern, Frank Schultmann: Secondary raw material markets in the C\&D sector: Study on user acceptance in southwest Germany

No. 38 Christoph Fraunholz, Dirk Hladik, Dogan Keles, Dominik Möst, Wolf Fichtner:On the Long-Term Efficiency of Market Splitting in Germany

No. 37 Christoph Fraunholz, Dogan Keles, Wolf Fichtner:On the Role of Electricity Storage in Capacity Remuneration Mechanisms

No. 36 Hansjörg Fromm, Lukas Ewald, Dominik Frankenhauser, Axel Ensslen, Patrick Jochem: A Study on Free-floating Carsharing in Europe Impacts of car2go and DriveNow on modal shift, vehicle ownership, vehicle kilometers traveled, and $\mathrm{CO}_{2}$ emissions in 11 European cities

No. 35 Florian Zimmermann, Andreas Bublitz, Dogan Keles, Wolf Fichtner: Cross-border effects of capacity remuneration mechanisms: the Swiss case

No. 34 Judith Auer: Ladeinfrastruktur für Elektromobilität im Jahr 2050 in Deutschland

No. 33 Jann Weinand, Max Kleinebrahm, Russell McKenna, Kai Mainzer, Wolf Fichtner: Developing a three-stage heuristic to design geothermalbased district heating systems

No. 32 Daniel Fehrenbach: Modellgestützte Optimierung des energetischen Eigenverbrauchs von Wohngebäuden bei sektor-gekoppelter Wärmeversorgung -Vorstellung des POPART-Modells

No. 31 Jann Weinand, Russell McKenna, Katharina Karner, Lorenz Braun, Carsten Herbes: Assessing the potential contribution of excess heat from biogas plants towards decarbonisingGerman residential heating

No. 30 Daniel Heinz: Erstellung und Auswertung repräsentativer Mobilitäts-und Ladeprofile für Elektrofahrzeuge in Deutschland

No. 29 Alexander Harbrecht, Russell McKenna, David Fischer, Wolf Fichtner: Behavior-oriented Modeling of Electric Vehicle Load Profiles: A Stochastic Simulation Model Considering Different Household Characteristics, Charging Decisions and Locations

No. 28 Felix Hübner, Sven Möller, Frank Schultmann: Entwicklung eines Expertensystems für die Planung kerntechnischer Rückbauprojekte

The responsibility for the contents of the working papers rests with the author, not the institute. Since working papers are of preliminary nature, it may be useful to contact the author of a particular working paper about results or caveats before referring to, or quoting, a paper. Any comments on working papers should be sent directly to the author. 


\section{Impressum}

Karlsruher Institut für Technologie

Institut für Industriebetriebslehre und Industrielle Produktion (IIP) Deutsch-Französisches Institut für Umweltforschung (DFIU)

Hertzstr. 16

D-76187 Karlsruhe

KIT - Universität des Landes Baden-Württemberg und

nationales Forschungszentrum in der Helmholtz-Gemeinschaft

Working Paper Series in Production and Energy

No. 42, April 2020

ISSN 2196-7296 